\title{
Adverse prognosis of epigenetic inactivation in RUNX3 gene at I p36 in human pancreatic cancer
}

\author{
S Nomoto*,', T Kinoshita', T Mori', K Kato', H Sugimoto', N Kanazumi', S Takeda' and A Nakao' \\ 'Department of Surgery II, Graduate School \& Faculty of Medicine, University of Nagoya, Nagoya, Japan
}

\begin{abstract}
Alteration in transforming growth factor- $\beta$ signalling pathway is one of the main causes of pancreatic cancer. The human runt-related transcription factor 3 gene (RUNX3) is an important component of this pathway. RUNX3 locus I 36 is commonly deleted in a variety of human cancers, including pancreatic cancer. Therefore, we examined genetic and epigenetic alterations of RUNX3 in human pancreatic cancer. Thirty-two patients with pancreatic cancer were investigated in this study. We examined the methylation status of RUNX3 promoter region, loss of heterozygosity $(\mathrm{LOH})$ at I 36 , and conducted a mutation analysis. The results were compared with clinicopathological data. Promoter hypermethylation was detected in 20 (62.5\%) of 32 pancreatic cancer tissues, confirmed by sequence of bisulphite-treated DNA. Loss of heterozygosity was detected in II (34.3\%) of 32 pancreatic cancers. In comparison with clinicopathological data, hypermethylation showed a relation with a worse prognosis $(P=0.0143)$. Hypermethylation and $\mathrm{LOH}$ appear to be common mechanisms for inactivation of RUNX3 in pancreatic cancer. Therefore, RUNX3 may be an important tumour suppressor gene related to pancreatic cancer.
\end{abstract}

British Journal of Cancer (2008) 98, 1690- 1695. doi:10.1038/sj.bjc.6604333 www.bjcancer.com

Published online 13 May 2008

(c) 2008 Cancer Research UK

Keywords: RUNX3; pancreatic cancer; hypermethylation; loss of heterozygosity

Despite its relatively low incidence of approximately 10 cases/ 100000 people, pancreatic cancer is still one of the leading causes of cancer-related death in industrialised countries including Japan. The prognosis remains poor, with an overall 5-year survival rate of less than $5 \%$ (Jemal et al, 2007). The pathogenesis of pancreatic ductal adenocarcinoma can be described as a step-by-step accumulation of genetic changes, such as K-ras oncogene mutations, p53, p16, and smad4 tumour suppressor gene mutations (Kern et al, 2002), in addition to several epigenetic alterations, which together result in self sufficiency of growth signals, insensitivity to antigrowth signals, evasion of apoptosis, angiogenesis, invasion, and metastasis (Ozawa et al, 2001). Recently, several reports indicated that every silencing mechanism, such as loss of heterozygosity (LOH) and mutations in a gene, or hypermethylation in its promoter region occurred in a tumour suppressor gene resulting in loss of its function in tumorigenesis (Tokumaru et al, 2003).

Transforming growth factor- $\beta$ (TGF- $\beta$ ) signalling is a wellestablished tumour suppressor pathway in pancreatic carcinogenesis (Massagu et al, 2000). Smad4 is a key transcription factor in the TGF- $\beta 1$ signalling pathway, and is inactivated in about $50 \%$ of pancreatic adenocarcinomas. The human runt-related transcriptional factor 3 (RUNX3) gene also plays important roles in the TGF- $\beta$ signalling pathway. In this pathway, Smad 2 and Smad3 activated by TGF- $\beta$ interact with RUNX3, and induce transcriptional activation of target genes in the nucleus (Ito and Miyazono, 2003; Miyazono et al, 2003).

*Correspondence: Dr S Nomoto; E-mail: snomoto@med.nagoya-u.ac.jp Received 24 August 2007; revised 31 January 2008; accepted 28 February 2008; published online 13 May 2008
RUNX3 induced apoptosis in epithelial cells, and the knockout mice of this gene showed hyperplasia in gastric mucosa. In addition, loss of function of RUNX3 caused by DNA hypermethylation, $\mathrm{LOH}$ at gene locus, and mutation correlated with the progression of primary gastric cancers ( $\mathrm{Li}$ et al, 2002). RUNX3 might have the important role of TGF- $\beta$ and Smad proteins in carcinogenesis. Furthermore, RUNX3 is located on the distal portion of the short arm of human chromosome 1 (1p36), which is commonly deleted in a variety of human cancers, including pancreatic cancer (Nowak et al, 2005; Loukopoulos et al, 2007). Therefore, the genetic and epigenetic alterations in RUNX3 may have an important role in pancreatic cancer.

The aim of our present study was to determine whether the RUNX3 gene alteration might have a role in carcinogenesis in pancreatic cancer. We examined $\mathrm{LOH}$ at this gene locus in $1 \mathrm{p} 36$ with microdissected DNA, the DNA-methylation status by methylation-specific polymerase chain reaction (MSP) and sequencing, and the mutation of RUNX3 by reverse transcription-polymerase chain reaction (RT-PCR) single-strand conformation polymorphism (RT-PCR-SSCP) in 32 primary pancreatic cancer tissues and corresponding noncancerous tissues. Then, we correlated these results with the clinicopathological data.

\section{MATERIALS AND METHODS}

\section{Patients, sample collection, microdissection, and DNA preparation}

Thirty-two primary pancreatic cancer tissues and corresponding noncancerous tissues were collected at Nagoya University Hospital from pancreatic cancer patients during pancreatico-duodenectomy, 
distal pancreatectomy, or total pancreatectomy. All tissues were diagnosed histologically as pancreatic cancer. Written informed consent, as required by the institutional review board, was obtained from all patients. Collected samples were stored immediately in liquid nitrogen at $-80^{\circ} \mathrm{C}$ until analysis. Genomic DNA was obtained from these samples by digestion with proteinase $\mathrm{K}$, followed by phenol/chloroform extraction.

Other parts of the specimens were formalin-fixed for $24 \mathrm{~h}$ and processed for paraffin embedding. From each tissue block, a series of four $5-\mu \mathrm{m}$ thick sections were cut. The first section was H\&E stained for pathologic evaluation; identification of the tumour epithelia. To avoid normal cell contamination, target epithelial cells from the cancer areas were produced by laser capture microdissection using a Pixcell LCM system (Arcturus Engineering Inc., Mountain View, CA, USA). An average of 200 laser shots $(30 \mu \mathrm{m}$ shot size, $60 \mathrm{~ms}$ laser pulse duration, and power of $60 \mathrm{MW}$ ) were used for each sample. Microdissected cells were then incubated overnight at $37^{\circ} \mathrm{C}$ in $50 \mu \mathrm{l}$ digestion buffer $\left(10 \mathrm{mmoll}^{-1}\right.$ Tris- $\mathrm{HCl}$ (pH 8.0), $1 \mathrm{mmoll}^{-1}$ EDTA, $1 \%$ Tween $20,1 \mathrm{mg} \mathrm{ml}^{-1}$ proteinase $\mathrm{K}$ ) and incubated at $95^{\circ} \mathrm{C}$ for $10 \mathrm{~min}$ to inactivate the proteinase $\mathrm{K}$.

\section{Microsatellite analysis}

DNAs from primary pancreatic cancer tissues and corresponding noncancerous tissues were analysed for $\mathrm{LOH}$ study by amplification of CA repeat sequences using PCR. DNAs of pancreatic cancer epithelia were collected by the microdissection method mentioned above.

Two microsatellite markers, D1S234 and D1S247, were used. D1S234 exists at only $900 \mathrm{~Kb}$ on the telomeric side from the RUNX3 locus, and D1S247 is centromeric from the RUNX3 locus. Polymerase chain reaction amplification was performed containing $\left[\alpha^{32} \mathrm{P}\right] \mathrm{dCTP}$ and $50 \mathrm{ng}$ of genomic DNA. Polymerase chain reaction products were analysed on a $6 \%$ polyacrylamide gel and processed by autoradiography. Allelic loss was scored when the band intensity of one allele was decreased significantly (more than $40 \%$ reduction) in tumour DNA as compared with that in the normal DNA by using a BASS-2000 image analyzer (Fuji Photo Film Co. Ltd, Tokyo, Japan).

\section{Methylation-specific PCR}

DNA from tumour and normal specimens was subjected to bisulphite treatment. Briefly, $2 \mu \mathrm{g}$ of DNA was denatured by $\mathrm{NaOH}$ and modified by sodium bisulphite. DNA samples were then purified using the Wizard purification resin (Promega Corp., Madison, WI, USA), treated again with $\mathrm{NaOH}$, precipitated with ethanol, and resuspended in water. The primer pairs for the unmethylated detecting were in RUNX3 promoter region near exon 1: S (sense, 5'-GTGGGTGGTTGTTGGGTTAGT-3') and AS (antisense, $5^{\prime}$-TCCTCAACCACCACTACCACA-3'), which amplify a 138-base pair (bp) product, and those for the methylated detecting were in the same region: $S$ (sense, $5^{\prime}$-CGTCGGGTTAGCGAGGTT TC- $3^{\prime}$ ) and AS (antisense, 5'-GCCGCTACCGCGAAAAACGA-3'), which amplify a 120 -bp product. The PCR amplification consisted of 35 cycles of $94^{\circ} \mathrm{C}$ for $20 \mathrm{~s}, 60^{\circ} \mathrm{C}$ for $20 \mathrm{~s}$, and $72^{\circ} \mathrm{C}$ for $15 \mathrm{~s}$, after the initial denaturation step $\left(94^{\circ} \mathrm{C}\right.$ for $\left.5 \mathrm{~min}\right)$. Each PCR product was loaded directly onto $2 \%$ agarose gels, stained with ethidium bromide, and visualised under UV illumination.

\section{Sequence analysis}

Genomic bisulphite-treated DNA of primary pancreatic cancer tissues was sequenced. Polymerase chain reaction was performed in methylated cases. The primer pairs for sequence were in RUNX3 promoter region near exon1: $S$ (sense, 5'-GTTTAGGTAGTAGG GATAGTT- $3^{\prime}$ ) and AS (antisense, 5'-CTATTCTCTCCCATCTTA CC- $3^{\prime}$ ), which amplify a 388 -bp product. The PCR amplification consisted of 36 cycles of $94^{\circ} \mathrm{C}$ for $30 \mathrm{~s}, 54^{\circ} \mathrm{C}$ for $30 \mathrm{~s}$, and $72^{\circ} \mathrm{C}$ for
$30 \mathrm{~s}$, after the initial denaturation step $\left(94^{\circ} \mathrm{C}\right.$ for $\left.5 \mathrm{~min}\right)$. Polymerase chain reaction products were purified directly using the QIA quick Gel Extraction Kit (QIAGEN, Hilden, Germany). Purified DNA fragments were subcloned into TA cloning vector (Invitrogen $^{\mathrm{TM}}$, Carlsbad, CA, USA). Six cloning samples were picked out from one methylated tumour tissue. Each cloning DNA was mixed with $3 \mu \mathrm{l}$ of specific primer (M13), $4 \mu \mathrm{l}$ of Cycle Sequence Mix (ABI PRISM Terminator v1.1 Cycle Sequencing Kit; Applied Biosystems, Foster City, CA, USA). Samples were subjected to the following cycling conditions: $95^{\circ} \mathrm{C}$ for $30 \mathrm{~s} ; 25$ cycles of $95^{\circ} \mathrm{C}$ for $15 \mathrm{~s}, 50^{\circ} \mathrm{C}$ for $15 \mathrm{~s}$, and $60^{\circ} \mathrm{C}$ for $4 \mathrm{~min}$ followed by purification by ethanol precipitation. Sequence analysis was carried out using an Applied Biosystems ABI310, and sequence electropherograms were generated by ABI Sequence Analysis 3.0.

\section{RT-PCR-SSCP}

Polymerase chain reaction amplification using random-primed cDNA of 32 primary pancreatic cancer tissues was performed using oligonucleotide primers in the presence of $\left[\alpha^{32} \mathrm{P}\right] \mathrm{dCTP}$, followed by electrophoretic separation on $6 \%$ nondenaturing polyacrylamide gels both in the presence of $5 \%$ glycerol at room temperature and in its absence at $4{ }^{\circ} \mathrm{C}$. RUNX3 ORF (1248-bp) is divided into four overlapped fragments and each fragment was amplified. The primer pairs used for RUNX3 mutation were S1 (sense, 5'-GCCGCTGTTATGCGTATTCC-3') and AS1 (antisense, 5'-CTCAGCGGAGTAGTTCTCGT-3'), amplifying a 370-bp fragment; S2 (sense, 5'-GTGACTGTGATGGCAGGCAA-3') and AS2 (antisense, $5^{\prime}$-GTTCCGAGGTGCCTTGGATT-3'), amplifying a 398-bp fragment; S3 (sense, $5^{\prime}$-ACAAGCCACTTCAGCAGCCA-3') and AS3 (antisense, 5-GAGAACTGGTAGGAGCCAGA-3'), amplifying a 368-bp fragment; S4 (sense, $5^{\prime}$-CTACCACCTCTACTACGG GA-3') and AS4 (antisense, 5'-CCCATCACTGGTCTTGAAGG-3'), amplifying a 326-bp fragment. The PCR amplification consisted of 35 cycles of $94^{\circ} \mathrm{C}$ for $30 \mathrm{~s}, 58^{\circ} \mathrm{C}$ for $30 \mathrm{~s}$, and $72^{\circ} \mathrm{C}$ for $30 \mathrm{~s}$, after the initial denaturation step $\left(94^{\circ} \mathrm{C}\right.$ for $\left.5 \mathrm{~min}\right)$ in $\mathrm{F} 1-\mathrm{R} 1$ and in the presence of $10 \%$ dimethylsulphoxide (F2-R2, F3-R3, F4-R4).

\section{Statistical analysis}

The correlation between the methylation status of RUNX3 mRNA and clinicopathological data was analysed by Fisher's exact test or $\chi^{2}$ test for independence. Overall survival rates were calculated using the Kaplan-Meier method, and difference in survival curves was analysed using the log-rank test. Independent prognostic factors were identified by multivariate analysis using the Cox proportional hazards regression model. Data are expressed as mean \pm s.d. Statistical significance was considered as $P<0.05$.

\section{RESULTS}

\section{Microsatellite analysis of RUNX3}

We first examined DNA samples obtained by microdissection from the 32 primary pancreatic cancer tissues and corresponding noncancerous tissues for $\mathrm{LOH}$ using two microsatellite markers, D1S234 and D1S247, which are close to the RUNX3 locus. D1S234 is telomeric and D1S247 is centromeric to the locus. Allelic imbalance in one or two markers was observed in $11(34.3 \%)$ of the 32 cases (Figure 1). We judged the 11 cases as having an $\mathrm{LOH}$ at the locus. The results are summarised in Table 1 . No cases evidenced microsatellite instability in this study. Two cases proved noninformative from using the two markers.

\section{Hypermethylation of RUNX3 promoter region in pancreatic cancer}

To investigate whether the gene silencing was due to hypermethylation of RUNX3, MSP was performed in the 32 primary pancreatic 
cancer tissues and corresponding noncancerous tissues. Promoter hypermethylation was detected in $20(62.5 \%)$ of the 32 primary pancreatic cancer tissues and in only two of the corresponding noncancerous tissues (Figure 1). To confirm the methylation of the RUNX3 promoter region, genomic bisulphite-treated DNA of primary pancreatic cancer tissues, which showed methylation by MSP, were sequenced. Every case showed at least one methylated CpG island of the sequenced fragments. A representative case is shown in Figure 2.

\section{Mutational analysis of $R U N X 3$ in pancreatic cancer tissues}

To investigate the mutation status of this gene, RT-PCR-SSCP analysis was performed. We could not see any aberrant bands

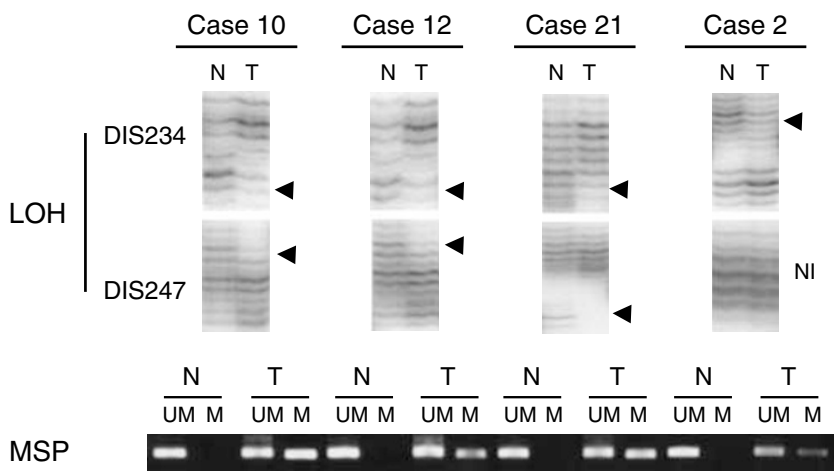

Figure I Representative results of $\mathrm{LOH}$ and MSP in cases 10, 12, 21, and 2. In the analysis of $\mathrm{LOH}$ at RUNX3 locus, cases 10, 12, and 21 showed allelic imbalance at DIS234 as well as at DIS247 (arrowheads). Case 2 showed allelic imbalance at DIS234 (arrowhead), but the DIS247 was not informative (NI). Promoter hypermethylation was observed in the DNA extracted from tumour tissue (T). In noncancerous samples $(N)$, a methylation band was not seen in any lane. All four cases showed both $\mathrm{LOH}$ and promoter hypermethylation. These results indicated that biallelic inactivation ( $\mathrm{LOH}$ at Ip36 + methylation) caused the inactivation of RUNX3 in pancreatic cancer. $\mathrm{LOH}$, loss of heterozygosity; MSP = methylation-specific PCR; RUNX3 = human runt-related transcription factor 3 gene.
(Figure 3). No mutations or polymorphisms were detected in the 32 pancreatic cancer tissues. As we used the bulk frozen samples, normal cells such as fibrosis cells were contaminated in the tumour tissues, making it difficult to identify aberrant bands.

\section{Statistical analysis of clinicopathological data and our findings}

Subsequently, we analysed the correlation between the clinicopathological data and results of our findings. Table 2 shows the correlation between the clinicopathological data and methylation status. Interestingly, RUNX3 hypermethylation was significantly correlated with a worse prognosis $(P=0.0143)$ (Figure 4$)$. No other correlation with any clinicopathological parameter was found.

To evaluate the value of $R U N X 3$ methylation as an independent prognostic determinant, multivariate analysis was performed with prognostic factors that had been found to be significant by univariate analyses. The analysis identified lymph node metastasis, invasion of retroperitoneal tissue, and hypermethylation of RUNX3 gene as the variables for independently predicting overall survival (Table 3).

\section{DISCUSSION}

Transforming growth factor- $\beta$ plays a key role in regulating the growth and differentiation of many cell types. In TGF- $\beta 1$-null

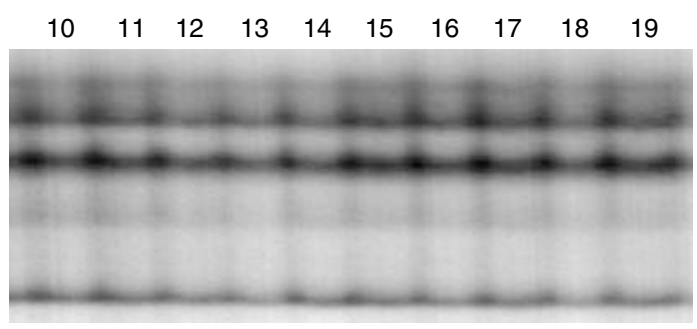

Figure 3 RT-PCR-SSCP analysis of RUNX3 in pancreatic cancer tissues. Representative results (cases 10-19) of RT-PCR-SSCP analysis using F2-R2 primer set. There were no aberrant bands in all cases. RT-PCR$\mathrm{SSCP}=\mathrm{RT}-\mathrm{PCR}$ single-strand conformation polymorphism; RUNX3 = human runt-related transcription factor 3 gene.

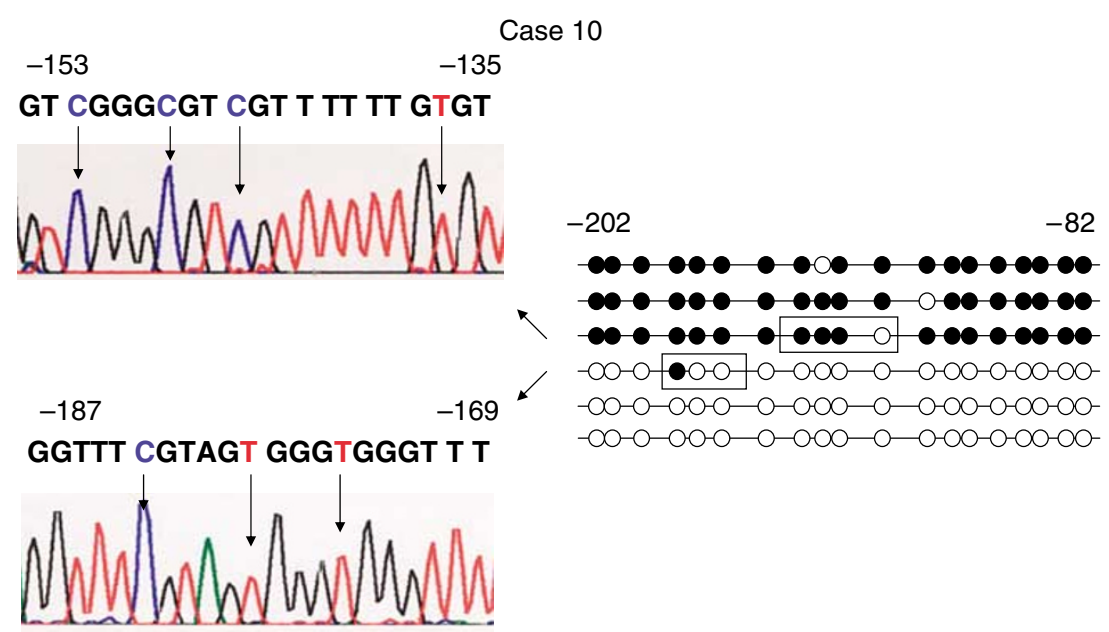

Figure 2 Sequence analysis of bisulphite-treated DNA from tumour sample of case 10 in RUNX3 promoter region. Methylation status of the 19 CpG islands between -82 and -202 from the transcription-initiation site of RUNX3 exon I is shown. The fragment was PCR amplified and subcloned into TA cloning vector. Closed circle indicates methylated $\mathrm{CpG}$ island, open circle indicates unmethylated $\mathrm{CpG}$ island. Each group of six clones showed a different methylation status. Arrows below the sequence indicate CpG islands. The Cs indicate methylated CpG islands. The Ts were converted from C by bisulphite treatment, indicating unmethylated CpG islands. RUNX3 = human runt-related transcription factor 3 gene. 
Table I Clinicopathological features and results of RUNX3 alterations in pancreatic cancer tissues

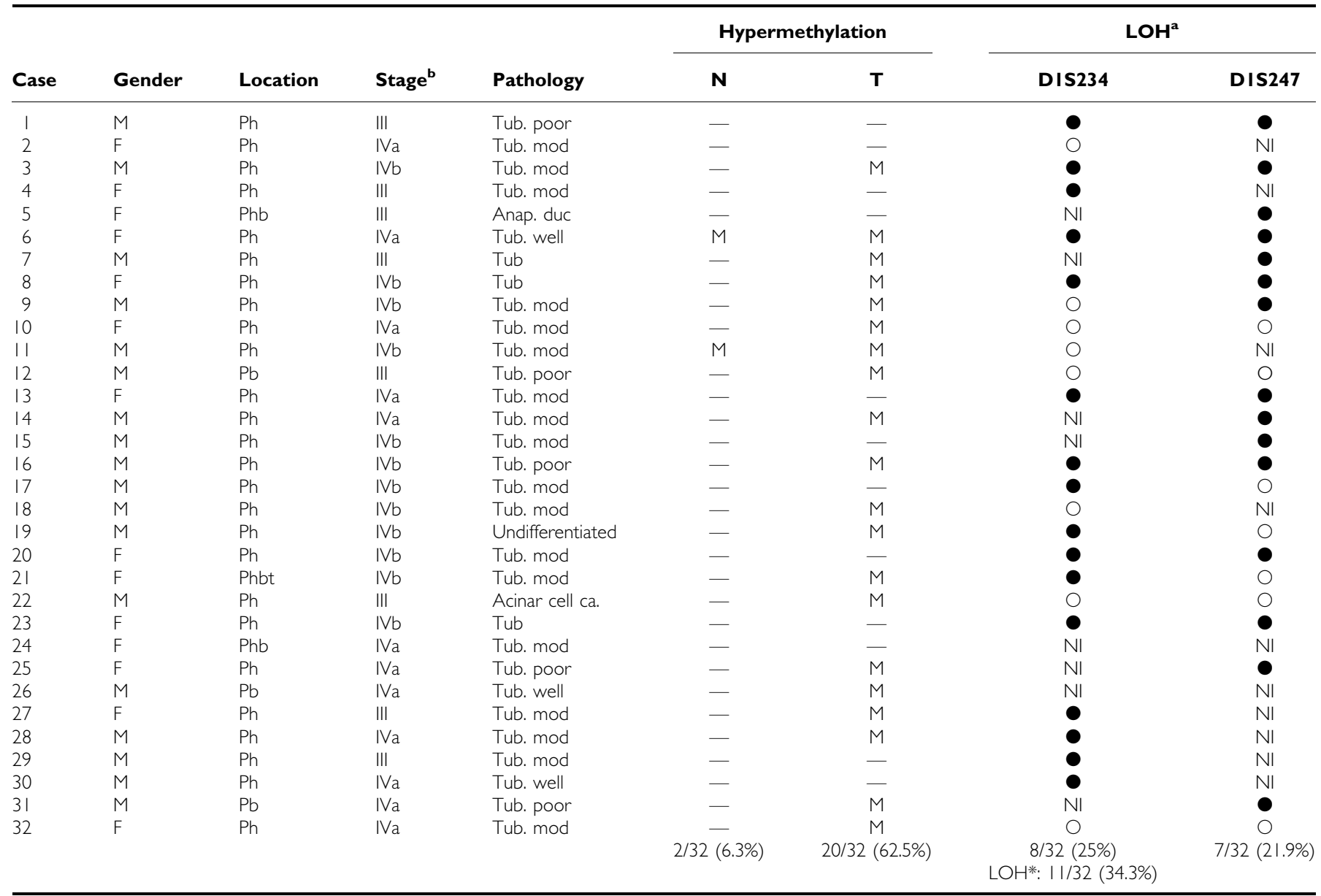

${ }^{a}$ Anap. duc = anaplastic ductal adenocarcinoma; $F=$ female; $L O H=$ loss of heterozygosity; $M=$ male; $M=$ methylated; mod=moderately differentiated adenocarcinoma; $\mathrm{N}=$ normal tissue; $\mathrm{NI}=$ not informative; $\mathrm{Pb}=$ pancreatic body; $\mathrm{Pt}=$ pancreatic tail; poor = poorly differentiated adenocarcinoma; $\mathrm{Ph}=$ pancreatic head; $\mathrm{T}=$ tumour tissue; tub = tubular adenocarcinoma; well = well-differentiated adenocarcinoma; ; - , unmethylated; open circle $=\mathrm{LOH}$ detected; closed circle = retention of heterozygosity; $\mathrm{LOH}^{*}=$ cases in which $\mathrm{LOH}$ was detected in at least one locus. ${ }^{\text {b }}$ The stage classification was performed according to the Pancreatic Cancer Study Group of Japan.

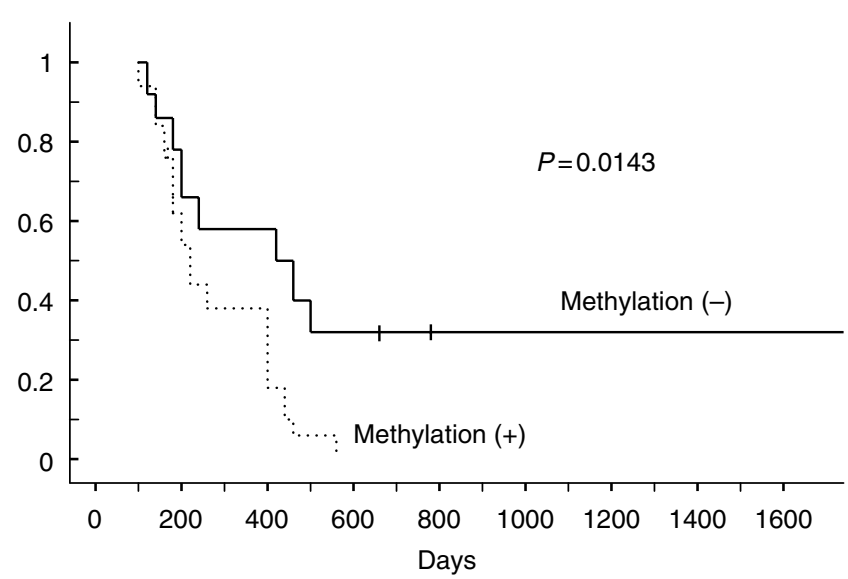

Figure 4 Survival stratified by methylation status in primary pancreatic cancer. RUNX3 hypermethylation was significantly correlated with a worse prognosis $(P=0.0143)$. RUNX3 = human runt-related transcription factor 3 gene.

animals, proliferation of the gastric epithelium is stimulated and hyperplasia occurs (Crawford et al, 1998). TGF- $\beta$ is known to be a potent inhibitor of pancreatic acinar and duct cell proliferation in vitro (Bisgaard and Thorgeirsson, 1991; Logsdon et al, 1992).
RUNX3 is a runt domain transcription factor involved in this signalling pathway. RUNX3 protein binds with the Smad2 and Smad3 proteins. Recently, it has been reported that RUNX3 was one of the tumour suppressor genes in gastric cancer and testicular yolk sac tumour. Runx3-null mice reportedly develop hyperplasia of the gastric mucosa through activation of cellular proliferation and suppression of apoptosis in epithelial cells (Li et al, 2002). Interestingly, 1p36, where RUNX3 exists, is a region commonly deleted in a wide variety of human carcinomas, including pancreatic cancer. To date, there are many reports regarding the TGF- $\beta$ signalling pathway in pancreatic cancer (e.g. TGF- $\beta$ receptor II, Smad2 and Smad4), but only a few deal with this gene's alterations in pancreatic cancer (Li et al, 2004; Wada et al, 2004). Moreover, there are no reports regarding primary pancreatic cancer. Our study further supports a role for RUNX3 in pancreatic cancer.

The 1 p36 region is believed to harbour tumour suppressor genes, because previous studies identified frequent allelic imbalance at $1 \mathrm{p} 36$ in various types of human cancers (Schwab et al, 1996). RIZ1 and p73 genes are located on 1p36, and LOH was detected at each gene locus in pancreatic cancer (Sakurada et al, 2001; Sphyris et al, 2004). It is thought that these are one of the tumour suppressor genes in pancreatic cancer, and we think that RUNX3 may also be a candidate.

Previously, Wada et al (2004) reported that nine of 12 pancreatic cancer cell lines exhibited no expression of RUNX3 by both 
Table 2 Clinicopathological features and results of RUNX3 hypermethylation in pancreatic cancer tissues

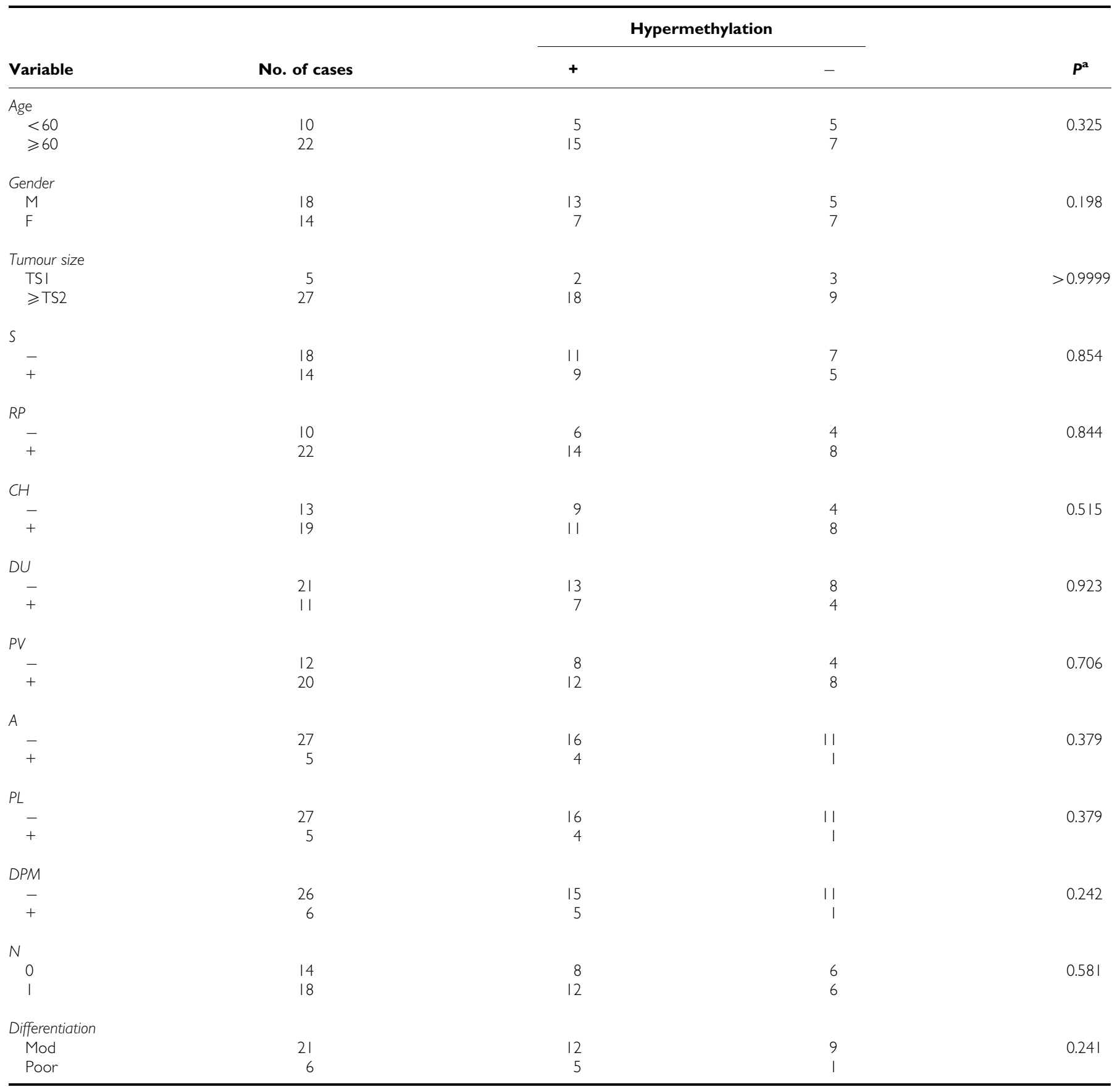

${ }^{a}$ Analysed by Fisher's exact test or $\chi^{2}$ test for independence. ${ }^{b}$ Tumour size according to the Classification of Pancreatic Carcinoma; $\mathrm{A}=$ arterial invasion; $\mathrm{CH}=$ choledocal invasion; $D P M=$ dissected peripancreatic tissue margin; $D U=$ duodenal invasion; $F=$ female; $P L=$ peripancreatic nerve plexus invasion; $M=$ male; $m o d=$ moderately differentiated adenocarcinoma; $N=$ lymph node metastasis; poor=poorly differentiated adenocarcinoma; $P T N M=$ pathological $T N M$; PV=portal vein invasion; $\mathrm{RP}=$ retroperitoneal invasion; $\mathrm{S}=$ serosal invasion. ${ }^{\circ}$ Classified according to the classification of The General Rules for the Clinical and Pathological Study of Primary Pancreatic Cancer. April 2002, Pancreatic Cancer Study Group of Japan.

Table 3 Multivariate analysis of patients with pancreatic cancer

\begin{tabular}{lccl}
\hline Variable & Odds ratio & $\mathbf{9 5 \%} \mathbf{~ C l}$ & $\boldsymbol{P}$ \\
\hline Tumour size $(\geqslant 2.0 \mathrm{~cm})$ & 1.995 & $0.639-6.226$ & 0.2342 \\
Lymph node metastasis & 2.388 & $1.026-5.561$ & $0.0435 *$ \\
Invasion of retroperitoneal tissue (d.p.m.) & 5.486 & $1.409-21.358$ & $0.0141 *$ \\
Invasion of plexus nerve $(\mathrm{Pl})$ & 1.759 & $0.591-5.239$ & 0.3103 \\
Hypermethylation & 3.157 & $1.226-8.130$ & $0.0172 *$ \\
\hline
\end{tabular}

*Statistical significance. $\mathrm{Cl}=$ confidence interval. northern blot analysis and RT-PCR. All of the nine cell lines showed methylation of the promoter $\mathrm{CpG}$ island of the gene. Moreover, hemizygous deletion of RUNX3, as detected by fluorescence in situ hybridisation, was found in most of the cell lines that lacked RUNX3 expression. Our results using primary pancreatic cancer tissue were compatible with their findings.

Li et al (2004) reported that RUNX3 expression was low-toabsent in normal pancreatic tissues, but increased in a third of cancer tissues by RT-PCR and immunohistochemistry. RUNX3 expression was present only in islets of the normal pancreas. They 
also found that all metastases of pancreatic cancer tissues were devoid of or displayed only very faint RUNX3 expression by immunostaining.

Some groups have advocated islet cells as the cells of origin of pancreatic ductal adenocarcinoma (Pour et al, 2003). This would mean that the islet cells in pancreatic tissue are the tissue-specific stem cells in which cancer cells begin from the alteration in the oncogenes or tumour suppressor genes. RUNX3 is expressed in the tissue-specific stem cells, and only in islet cells in normal tissue. When cancer tissue has grown from the tissue-specific stem cells, the cancer cells express the RUNX3 protein. Some cancer tissues do not express RUNX3. In those cancer cells, RUNX3 gene is methylated. In cases with metastatic lesions, more aggressive tumour cells from the original lesion exist, such as RUNX3methylated cells. Hence, the metastatic pancreatic cancer cells do not express RUNX3 gene.

Thus, it may be hypothesised that there is indeed loss of RUNX3 expression by promoter hypermethylation or $\mathrm{LOH}$ in some primary tumours compared with normal islets, and almost a complete loss in metastatic tumours. Our finding that the survival in methylated cases in RUNX3 gene was significantly worse than that in unmethylated patients is compatible with this hypothesis, although pointing to a tumour suppressor role for RUNX3 in pancreatic cancer.

Nine of $11 \mathrm{LOH}$ detected cases had hypermethylation of the RUNX3 promoter region. These findings imply that silencing of RUNX3 occurred biallelically. Complete silencing of this gene leads to the progression of cancer, and then relates to the worse prognosis.

In conclusion, we have clearly demonstrated for the first time that RUNX3 is frequently methylated in primary pancreatic cancer tissues, frequent hemizygous deletion occurs at its locus in $1 \mathrm{p} 36$, and RUNX3-inactivated cases showed worse survival. We propose that inactivation of RUNX3 plays an important role in alteration of the TGF- $\beta$ signalling pathway and in the tumorigenesis of pancreatic cancer.

\section{REFERENCES}

Bisgaard HC, Thorgeirsson SS (1991) Evidence for a common cell of origin for primitive epithelial cells isolated from rat liver and pancreas. J Cell Physiol 147: $333-343$

Crawford SE, Stellmach V, Murphy-Ullrich JE, Ribeiro SM, Lawler J, Hynes RO, Boivin GP, Bouck N (1998) Thrombospondin-1 is a major activator of TGF-betal in vivo. Cell 93: $1159-1170$

Ito Y, Miyazono K (2003) RUNX transcription factors as key targets of TGF-beta superfamily signaling. Curr Opin Genet Dev 13: $43-47$

Japan Pancreatic Society (2003) Classification of Pancreatic Carcinoma 2nd English edn, Tokyo: Kanehara

Jemal A, Siegel R, Ward E, Hao Y, Xu J, Murray T, Thun MJ (2007) Cancer statistics, 2007. CA Cancer J Clin 57: 43-66

Kern SE, Hruban RH, Hidalgo M, Yeo CJ (2002) An introduction to pancreatic adenocarcinoma genetics, pathology and therapy. Cancer Biol Ther 1: $607-613$

Li J, Kleeff J, Guweidhi A, Esposito I, Berberat PO, Giese T, Büchler MW, Friess H (2004) RUNX3 expression in primary and metastatic pancreatic cancer. J Clin Pathol 57: 294-299

Li QL, Ito K, Sakakura C, Fukamachi H, Inoue K, Chi XZ, Lee KY, Nomura S, Lee CW, Han SB, Kim HM, Kim WJ, Yamamoto H, Yamashita N, Yano $\mathrm{T}$, Ikeda T, Itohara S, Inazawa J, Abe T, Hagiwara A, Yamagishi H, Ooe A, Kaneda A, Sugimura T, Ushijima T, Bae SC, Ito Y (2002) Causal relationship between the loss of RUNX3 expression and gastric cancer. Cell 109: $113-124$

Logsdon CD, Keyes L, Beauchamp RD (1992) Transforming growth factorbeta (TGF-beta 1) inhibits pancreatic acinar cell growth. Am J Physiol 262: $364-368$

Loukopoulos P, Shibata T, Katoh H, Kokubu A, Sakamoto M, Yamazaki K, Kosuge T, Kanai Y, Hosoda F, Imoto I, Ohki M, Inazawa J, Hirohashi S (2007) Genome-wide array-based comparative genomic hybridization

analysis of pancreatic adenocarcinoma: identification of genetic indicators that predict patient outcome. Cancer Sci 98: $392-400$

Massagu J, Blain SW, Lo RS (2000) TGF $\beta$ signaling in growth control, cancer, and heritable disorders. Cell 103: 295-309

Miyazono K, Suzuki H, Imamura T (2003) Regulation of TGF-beta signaling and its roles in progression of tumors. Cancer Sci 94: 230-234

Nowak NJ, Gaile D, Conroy JM, McQuaid D, Cowell J, Carter R, Goggins MG, Hruban RH, Maitra A (2005) Genome - wide aberrations in pancreatic adenocarcinoma. Cancer Genet Cytogenet 161: 36-50

Ozawa F, Friess H, Tempia-Caliera A, Kleeff J, Büchler MW (2001) Growth factors and their receptors in pancreatic cancer. Teratog Carcinog Mutagen 21: $27-44$

Pour PM, Pandey KK, Batra SK (2003) What is the origin of pancreatic adenocarcinoma? Mol Cancer 2: 13

Sakurada K, Furukawa T, Kato Y, Kayama T, Huang S, Horii A (2001) RIZ, the retinoblastoma protein interacting zinc finger gene, is mutated in genetically unstable cancers of the pancreas, stomach, and colorectum. Genes Chromosomes Cancer 30: 207-211

Schwab M, Praml C, Amler LC (1996) Genomic instability in 1p and human malignancies. Genes Chromosomes Cancer 16: 211-229

Sphyris N, Morris RG, Harrison DJ (2004) Induction of p21 and nuclear accumulation of TAp73alpha and c-abl during apoptosis of cisplatintreated primary pancreatic acinar cells. Int J Oncol 25: 1661-1670

Tokumaru Y, Nomoto S, Jerónimo C, Henrique R, Harden S, Trink B, Sidransky D (2003) Biallelic inactivation of the RIZ1 gene in human gastric cancer. Oncogene 22: 6954-6958

Wada M, Yazumi S, Takaishi S, Hasegawa K, Sawada M, Tanaka H, Ida H, Sakakura C, Ito K, Ito Y, Chiba T (2004) Frequent loss of RUNX3 gene expression in human bile duct and pancreatic cancer cell lines. Oncogene 23: $2401-2407$ 